\title{
Seismic analysis: past, present and the future
}

\author{
D. Mestrovic, D. Cizmar \& P. Roncevic \\ Faculty of Civil Engineering, University of Zagreb, Croatia
}

\begin{abstract}
This paper summarizes earthquake calculations according to Eurocode regulations and codes applied in Croatia (Europe). The paper shows past, present and future methods for determination of seismic forces - an overview of all methods used is given. A simple pseudo static calculation is analyzed and compared to seismic forces according to Eurocode. An overview of spectral analysis according to Eurocode and Croatian code is given and discussed. Finally, time history analysis is discussed because as computer power increases with the availability of the strong motion database, the real records are becoming more popular for defining the input to dynamic analyses. The paper discuses three basic methods of input data - artificial records, synthetics accelograms and real records recorded during earthquakes. The possibility of using real records (for both linear and non-linear time history) is analyzed and discussed. A conclusion about the use of real accelograms (time history) versus spectral analysis is given.
\end{abstract}

Keywords: seismic analysis, time history, accelogram.

\section{Introduction}

An earthquake is a phenomenon that results from the sudden release of stored energy in the Earth's crust that creates seismic waves. At the Earth's surface, earthquakes manifest themselves by a shaking or displacement of the ground. Earthquakes are related to the tectonic nature of the Earth. The Earth's lithosphere is a composed of plates in very slow but constant motion caused by the heat in the Earth's mantle and core. Plate boundaries can grind past each other, creating frictional stress. When the frictional stress exceeds a critical value, a sudden failure occurs. The boundary of tectonic plates along which failure occurs is called the fault plane. When the failure at the fault plane results in a displacement of the Earth's crust, the elastic strain energy is released and 
seismic waves are radiated, causing an earthquake. The severity of an earthquake is described by magnitude and intensity. Magnitude characterizes the size of an earthquake by measuring indirectly the energy released (Richter scale). Intensity indicates the local effects and potential for damage produced by an earthquake on the Earth's surface as it affects humans, animals, structures and natural objects. To be able to show the extent of various levels of seismic effects within a particular location, seismologists usually compile maps called isoseismic maps. An isoseismic map uses contours to outline areas of equal value in terms of ground shaking intensity, ground surface liquefaction, shaking amplification, or other seismic effects. Fig. 1 shows a typical isoseismic map. On the other hand, in building codes, the isoseismic maps are converted into seismic zone maps, which are used for seismic analysis of structural components of buildings. The seismic zone maps show the severity of expected earthquake shaking for a particular level of probability.

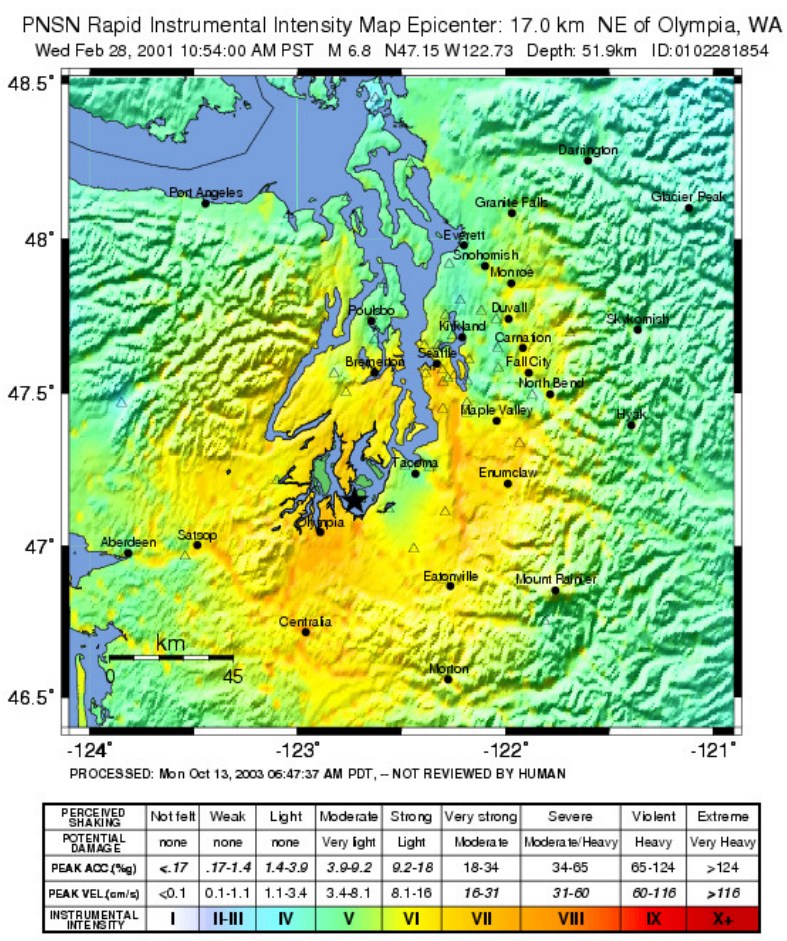

Figure 1: An isoseismic map (source: United States Geographical Survey).

\section{Model of structure}

This paper analyzes a simple five-storey reinforced concrete building which is situated in a seismically active region of Croatia. The structure is modeled as a simple plane frame. Each frame is made of concrete C25 according to 
Eurocode 2. Columns are $60 / 60 \mathrm{~cm}$ for the first two stories, other columns (stories three to five) are $40 / 40 \mathrm{~cm}$. Beams are for the first storey $30 / 70 \mathrm{~cm}$, for all others $55 / 70 \mathrm{~cm}$. Fig. 2 shows a model of the structure (units are in centimeters).

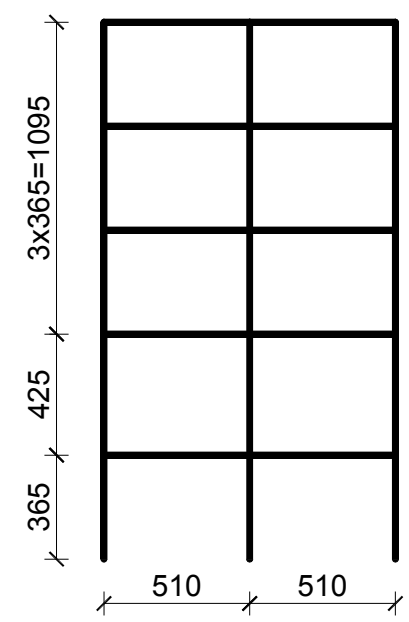

Figure 2: $\quad$ Model of concrete frame.

\section{Seismic analysis - overview of methods}

The focus of this paper is the comparison between different methods of obtaining seismic forces. The paper will analyze a five-storey reinforced concrete building which is situated in a seismically active region of Croatia. The structure is modelled as a simple plane frame. Several different calculations are made (pseudo static, spectrum analysis, non-linear time history and pushover). Pseudostatic analysis is made according to Croatian regulations. The structure is also analyzed using spectrum analysis according to EC8 (for this type of analysis both the elastic and design spectra are computed and discussed). Non-linear time history analysis is made using two synthetic accelograms that represent earthquakes in this region. Based on available digitized accelograms, two earthquakes were selected according to their magnitudes: an earthquake occurring in Petrovac (Montenegro) on April 15, 1979, with magnitude $M=6.8$ and an earthquake occurring on April 9, 1979, in Ulcinj (Montenegro) with magnitude $\mathrm{M}=5.3$.

\subsection{Pseudo-static analysis}

Pseudo-static analysis is made according to Croatian regulations. Total base shear (S) is calculated according to Eqn. (1) ( $\mathrm{K}$ is the total seismic coefficient, $\mathrm{G}$ is the total weight of structure, $G_{i}$ is the weight of each floor). The total seismic coefficient is given in Eqn. (2) $\left(\mathrm{K}_{\mathrm{o}}\right.$ is the coefficient depending on the class of 
the structure, $\mathrm{K}_{\mathrm{s}}$ depends on the seismic intensity, $\mathrm{K}_{\mathrm{d}}$ depends upon the natural period of the structure and $K_{p}$ is the coefficient that accounts for ductility and damping). For the purpose of this analysis $\mathrm{K}_{\mathrm{S}}=0.1$ and all other coefficients are equal to 1 , so $\mathrm{K}=0.1$.

$$
\begin{gathered}
\mathrm{S}=\mathrm{K} \cdot \mathrm{G} \\
\mathrm{K}=\mathrm{K}_{\mathrm{o}} \cdot \mathrm{K}_{\mathrm{S}} \cdot \mathrm{K}_{\mathrm{d}} \cdot \mathrm{K}_{\mathrm{p}}
\end{gathered}
$$

For structures up to five stories the seismic force for each floor $\left(\mathrm{S}_{\mathrm{i}}\right)$ is calculated as in Eqn. (3). For structures with more than five stories $15 \%$ of the total force is applied at the top level and the remaining $85 \%$ is calculated as in Eqn. (3).

$$
S_{i}=S \cdot \frac{G_{i} \cdot H_{i}}{\sum G_{i} \cdot H_{i}}
$$

\subsection{Spectrum analysis}

Frames are also analyzed using spectrum analysis according to EC8. The ground type is A (rock or other rock-like geological formation). Damping is assumed to be $5 \%$. Fig. 4 . shows the spectrum functions that were used as input for spectrum analysis (both the elastic and design spectra are computed). For the design spectrum a behavior factor of 4 is assumed.

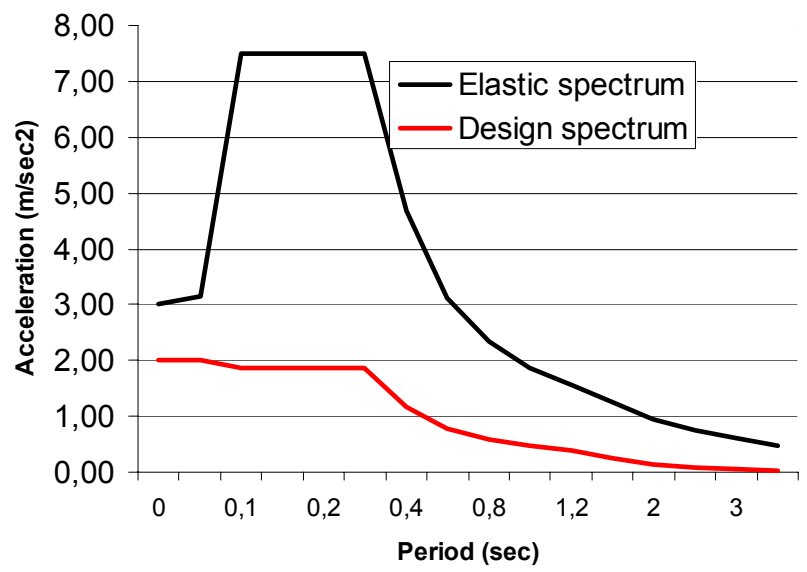

Figure 3: $\quad$ Spectrum function used for spectral analysis.

\subsection{Linear and non-linear time history analysis}

There are three basic options available for obtaining acceleration time-series: artificial earthquakes generated by software, synthetic accelograms and real records from earthquakes. For artificial earthquake generation a common 
approach is to generate a power spectral density function from the smoothed response spectrum, and then to derive sinusoidal signals having random phase angles and amplitudes. In this way we can generate many earthquakes very easily. But we should never forget that there is a big problem with artificial records: they usually have an excessive number of cycles of strong motion and they possess high energy content. Secondly, there is a possibility to generate a synthetic accelogram. Synthetic accelograms are generated from seismological source models and account for path and site effects. Models for generation of synthetic accelograms are very complex and usually an engineer must work with the seismologist. The third and most interesting to us are real records recorded during earthquakes. These accelograms are free from all problems associated with artificial spectrum-compatible records. They are better than synthetic accelograms because little knowledge of seismology is required. Real records are now easily accessible in large numbers, but for a specific location there aren't many recorded earthquakes.

For this paper linear and non-linear time history analyses are made using a synthetic accelogram that represents an earthquake in this region. Based on available digitized accelograms, two earthquakes were selected according to their magnitudes: an earthquake occurring in Petrovac (Montenegro) on April 15, 1979, with magnitude $M=6.8$ and an earthquake occurring on April 9, 1979, in Ulcinj (Montenegro) with magnitude $M=5.3$. From these earthquakes, the synthetic accelogram was generated. A calculation was made for a synthetic time sequence of accelerations which, on the average, correspond to earthquakes with magnitude 7.0 and epicentre distance $0 \mathrm{~km}$. $10 \mathrm{~m}$ hypocenter depth was generally assumed. Fig. 4 represents an accelogram which was used for both linear and non-linear analyses.

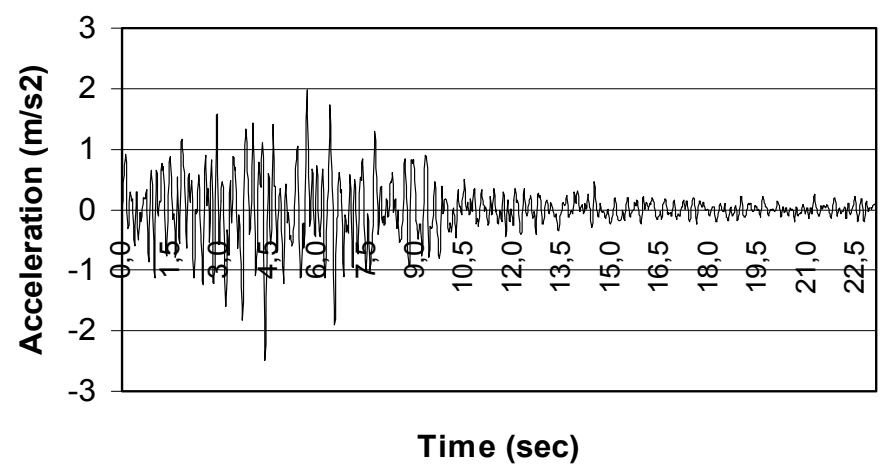

Figure 4: Accelogram used for time history analysis.

\subsection{Pushover analysis}

Non-linear pushover analysis is made for seismic assessment of the structure. The analysis was displacement controlled. The maximum displacement was 70 $\mathrm{cm}$. The non-linear behavior occurs in discrete hinges. Hinges are introduced 
into the frame and assigned at the end of columns and beams. A coupled hinge that yields results based on the interaction of the axial force and the bending moments at the hinge location is used.

Table 1: $\quad$ Results of different types of analyses.

\begin{tabular}{|l|c|c|}
\hline \multicolumn{1}{|c|}{ Type of analysis } & $\begin{array}{c}\text { Total base shear } \\
(\mathbf{k N})\end{array}$ & $\begin{array}{c}\text { Maximal column } \\
\text { shear }(\mathbf{k N})\end{array}$ \\
\hline Pseudo static & 181.6 & 79.7 \\
\hline Spectrum - elastic & 192 & 70.0 \\
\hline Spectrum - design & 52.7 & 21.7 \\
\hline Linear time-history & 603.9 & 248.5 \\
\hline $\begin{array}{l}\text { Non-linear time } \\
\text { history }\end{array}$ & 445.4 & 173.6 \\
\hline
\end{tabular}

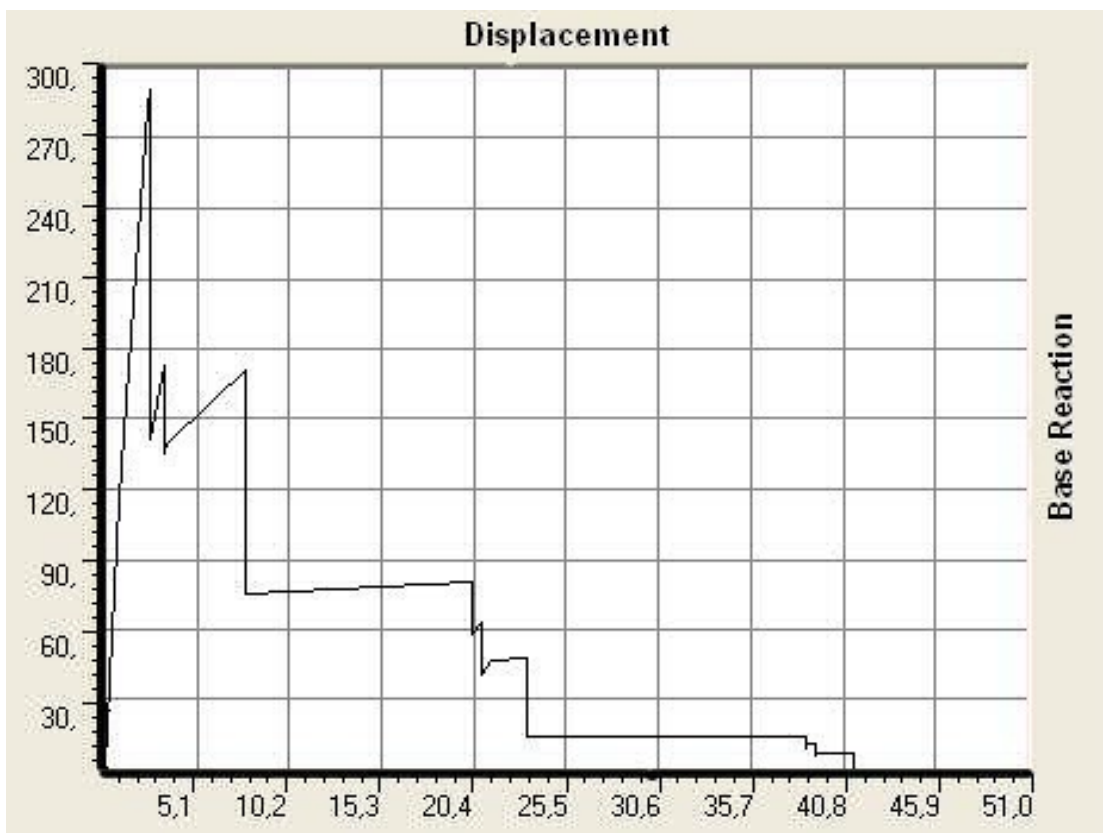

Figure 5: Pushover curve.

\section{Results}

Table 1 show results for a five-storey frame. Different types of analyses show very large numerical differences. It is evident that the design spectrum has smallest seismic forces (base shear is around $3 \%$ of total vertical load). This is 
because of the relatively great behaviour factor that was assumed. On the other hand elastic spectrum analysis has a base shear around $12.6 \%$. Pseudo static analysis has $10 \%$ base shear. Due to the very strong earthquake generated, the linear time history has the greatest seismic forces. Non-linear time history analysis has around 40-50\% less forces, mainly due to the non-linear distribution of forces. Fig. 5 shows the pushover curve (base reaction vs. displacement) for the same frame. It is very clear how the seismic capacity of the structure is decreasing with the increase of the horizontal displacement.

\section{Conclusion about the future of seismic analysis}

Today, the use of pseudo-static analysis is totally abandoned. Most structures are calculated using spectrum analysis, which is very easy to perform, and time history. Time history and pushover analysis are used more often for highly irregular structures and structures for which higher modes are likely to be excited. So now many questions arise: should we abandon spectrum analysis and use only time history and pushover? The answer is yes, but only when sufficient data is available. When using time history, we suggest using several accelograms with different epicenter distances. With more real earthquakes in a database it will be possible to conduct real accelograms and full time history. Other ways to perform full dynamic analysis is to generate synthetic accelograms for each seismic region.

\section{References}

[1] J. J. Bommer, A.B. Acevedo, "The use of real accelograms as input for dynamic analysis", Journal of Earthquake Engineering Vol. 8, London, 2004.

[2] W. Spence, S. A. Sipkin, G. L. Choy, "Measuring the size of earthquake", Unites States Geographical Survey, Reston, 1989.

[3] D. Cizmar, A. Nizic, D. Mestrovic, "Importance of dynamic characteristics of accelograms to structural response", SECED Conference, 2005.

[4] A. Mihanovic, "Dynamics of structures", University of Split - Faculty of Civil Engineering, 1995.

[5] SeismoSoft [2004] "SeismoSignal - A computer program for signal processing of strong-motion data" [online]. Available from URL: http://www.seismosoft.com.

[6] M. Causevic, "Earthquake engineering", University of Rijeka, Rijeka, 2001.

[7] E. Prelogovic, B. Aljinovich, and S. Bahun, "New data on structural relationship in the north Dalmatian Dinaride area": Geologia Croatica, v. 48 , no. 2,1985 